\title{
EL JURAMENTO DE FIDELIDAD A OCTAVIANO DEL AÑO 32 A. C.
}

\author{
Octavian's Oath of Loyalty in 32 B. C
}

María Concepción ROSADO MARTÍN

Universidad de Salamanca

E-mail: samarteca@usal.es

Fecha recepción: $19-01-2010$

Fecha de aceptación: 29-01-2010

\begin{abstract}
RESUMEN: El juramento de fidelidad del año 32 a. C. situó a Octaviano al frente de un bloque, liderado por Italia y secundado por las provincias occidentales, preparado para enfrentarse a Marco Antonio, quien estaba secundado por Cleopatra y por los territorios orientales. Suetonio, Dión Casio y el propio Augusto en las Res Gestae Divi Augusti nos han transmitido la existencia de este juramento. El texto original no se conserva por lo que se ha comparado con otros juramentos de fidelidad, tanto de época republicana como imperial. Nuestro objetivo es estudiar cómo se gestó este juramento, en qué consistía y analizar otros juramentos de fidelidad parecidos al del año 32 a. C. Con este juramento, Italia y Occidente quedaron unidos políticamente a Octaviano de cara al inminente enfrentamiento de éste contra Marco Antonio cuya consecuencia será el paso de la República al Principado.
\end{abstract}

Palabras Clave: Ius iurandum, fides, clientela, Octaviano, Italia, Occidente romano.

ABSTRACT: The oath of loyalty in $32 \mathrm{BC}$ put Octavian ahead of an alliance which was led by Italy, seconded by western provinces and it was ready to fight against Mark Anthony, who was seconded by Cleopatra and eastern territories. Suetonius, Dio Cassius and Augustus himself talk about this oath. The original text does not survive so the modern historians have compared this oath with republican and imperial oaths. Our objective is study how developed this oath, its contents and analyse other oath of loyalty seem this of 32 BC. By this oath, Italy and the Roman West joined politically Octavian with a view to the imminent war against Mark Anthony and this struggle would be the way from the Republic to 
the Principate.

Keywords: Oath, Loyalty, Clients, Octavian, Italy, the Roman West.

Octaviano, debido a los diferentes repartos de provincias (Pacto de Bolonia del año 43 a. C. y Acuerdo de Brindisi del año 40 a. C.) realizados durante el Segundo Triunvirato, centró todos sus esfuerzos en ganarse el apoyo de los territorios occidentales. Para conseguir esto, tuvo que derrotar a Sexto Pompeyo en Sicilia, expulsar a Lépido del triunvirato, pacificar Galia e Hispania y proteger el nordeste de Italia conquistando Iliria. Con todas estas acciones, llevadas a cabo entre el año 43 a. C., año en el que se constituyó el triunvirato, y el año 33 a. C., año en el que finalizaron las campañas militares en tierras ilirias, Octaviano había completado la parte territorial de su progrma y el siguiente paso que debía dar era conseguir que toda la zona occidental se uniera a él políticamente. Las actuaciones que tuvieron lugar en este sentido hay que comprenderlas en el marco de la guerra civil que iba a estallar y en la lucha por el poder entre Octaviano y Marco Antonio en el contexto de la crisis de la República.

La labor realizada por Agripa como edil de Roma en el año 33 a. C., además de embellecer la ciudad, sirvió para que Octaviano se ganase el apoyo de la mayor parte de la población de Roma, que se benefició del arreglo de los edificios públicos, de todas las calles, de la limpieza del alcantarillado y de la mejora en el aprovisionamiento de agua a través de la construcción de una serie de acueductos. A esto hay que añadir que Agripa amplió los ludi publici a 59 días y distribuyó gratuitamente aceite y sal. La entrada a los baños era libre, podían afeitarse a cuenta del edil, en el teatro se tiraban fichas al pueblo que equivalían a dinero o ropa y en el circo se exponían cosas de gran belleza que estaban a disposición de quien las quisiera. Como señala Zanker, "todo esto eran demostraciones de que con Octaviano se podría vivir mejor en el futuro"1.

Una última acción que resultó clave para que Octaviano se ganase el apoyo de la plebe fue que Agripa echase a los magos, charlatanes y astrólogos porque eran un medio de propaganda favorable a Marco Antonio y Cleopatra. Fue una medida de carácter político que facilitó el camino hacia una manipulación casi completa de la opinión pública a favor de la facción encabezada por Octaviano. Esta acción y las demás medidas adoptadas por Agripa, como apunta Roddaz, predispondrían a la población de Roma para apoyar a Octaviano en el juramento del año 32 a. C. ${ }^{2}$

Por tanto, este juramento del año 32 a. C. se empezó a gestar durante la edilidad de Agripa gracias a la cual Octaviano controló, casi de manera total, la opinión pública, algo clave si tenemos en cuenta que en aquel mo- 
mento, en el año 33 a. C., Italia estaba entregada al caos que estaban causando los partidarios de Marco Antonio, quienes estaban sobornando a civiles y soldados.

Ya en el año 32 a. C., el cónsul Sosio, en una sesión del Senado celebrada el 1 de enero, atacó duramente a Octaviano, pues se dedicó a alabar a Marco Antonio intentando poner al Senado en contra del primero. El tribuno Nunio Balbo evitó que Sosio consiguiera su objetivo aunque nadie sabía si este tribuno estaba al servicio de Octaviano para proteger sus intereses o, por el contrario, servía a Marco Antonio para salir en defensa del triunviro si el Senado se mostraba hostil al mismo 3 .

Cuando Sosio pronunció su discurso en el Senado, Octaviano estaba concentrando a sus seguidores de las ciudades italianas. Al regresar a Roma, convocó al Senado delante del cual se presentó rodeado de una guardia de soldados y amigos armados. Frente a lo defendido por Sosio, Octaviano respondió con acusaciones contra Marco Antonio y Cleopatra (seguramente aludiría a la vida de luxuria que llevaban los dos en Alejandría y a que Marco Antonio prefería estar en esa ciudad egipcia en vez de en Roma), ofreciendo la posibilidad de aportar pruebas que avalaran lo que estaba diciendo. Como consecuencia de ello, la oposición que existía hacia Octaviano huyó ya que los dos cónsules, Sosio y Domicio Ahenobarbo, y otros 300 senadores más se unieron a Marco Antonio en Éfeso. Con estos senadores huidos Marco Antonio estableció un senado paralelo al de Roma. En esta ciudad, Octaviano nombró cónsules a los que hasta ese momento eran cónsules suffecti, M. Valerio, pariente de Mesala Corvino y L. Cornelio Cinna, nieto del enemigo de Sila. Estos nombres históricos, según una conjetura de Syme, "podrían ofrecer garantía o, por lo menos, hacer creer al público que Octaviano contaba con el respaldo de la aristocracia romana"4.

A pesar de que los enemigos declarados de Octaviano hubieran huído de Roma, éste, para afianzar definitivamente su posición, necesitaba conseguir la justificación moral de la guerra y el apoyo moral del pueblo romano ${ }^{5}$. Para ello, Octaviano consiguió que el Senado cancelara todos los poderes de Marco Antonio y él mismo se convirtió en jefe supremo del Occidente romano a través de un juramento que fue respaldado, durante el verano del año 32 a. C., por toda Italia y las provincias occidentales de Galia, Hispania, África, Cerdeña y Sicilia.

Para conseguir este juramento, los agentes de Octaviano recurrieron a todo tipo de medios, como la intimidación y otros más complejos realizados por políticos locales que servían a hombres de Roma. En Italia fue suficiente la presencia de miles de veteranos devotos de Octaviano ya que, por ejemplo, los centuriones que formaban parte de las curias municipales hicieron uso de su influencia en sus respectivas ciudades para que éstas se mostrasen fa- 
vorables al juramento. Los veteranos que habían servido bajo las órdenes de Marco Antonio no se opusieron al juramento pues Octaviano les había dado tierras pasando, de este modo, a ser su nuevo patrono y defensor. En Arezzo no hubo ninguna oposición por ser de allí Mecenas y, tampoco, la hubo en otras ciudades donde Octaviano contaba con parientes y amigos. Para Syme, el juramento de fidelidad "no fue un solo acto, dispuesto por un decreto del líder cesariano y ejecutado simultáneamente en toda Italia, sino más bien la culminación, durante el verano, de una serie de agitaciones locales, que si bien lejos de no estar dirigidas, presentaban un cierto aspecto de espontáneas" ". En las provincias occidentales, las colonias de veteranos, que habían sido la base fundamental de Octaviano en estos territorios, apoyaron abiertamente el juramento y, además, muchas familias importantes se mostraron partidarias de Octaviano pudiendo citar, por ejemplo, a los Balbos de Gades que intervinieron en la vida política gaditana para que su ciudad siempre se mostrara partidaria de Octaviano ${ }^{7}$.

Dión Casio, Suetonio y el propio Augusto en las Res Gestae Divi Augusti nos han transmitido la existencia de este juramento ${ }^{8}$. Dión Casio nos informa de que Octaviano obtuvo, en primer lugar, el apoyo de Italia donde, incluso, atrajo hacia su causa a aquellos que habían sido establecidos por Marco Antonio en colonias prometiéndoles recompensas o recurriendo directamente a las amenazas. Sin embargo, Suetonio nos ha transmitido que los habitantes de la actual Bolonia fueron excluidos de la obligación de prestar juramento a Octaviano por ser una ciudad cliente, desde hacía tiempo, de la gens Antonia. Además de Italia, Dión Casio señala que Octaviano contó con el respaldo de Galia, Hispania, Cerdeña, Sicilia y las dos Áfricas, es decir, los territorios donde se hablaba latín (menos Cirenaica) y las tierras por donde se habían extendido los dominios de los monarcas de Mauretania, Bogud y Bocco II. Esta información sobre África de Dión Casio entra en contradicción con las Res Gestae Divi Augusti donde aparece una única África. Además, en el testamento político de Augusto, éste señala que habría sido el pueblo romano quien, por voluntad propia, lo habría elegido como jefe de la guerra, $d u x$, contra Marco Antonio. Está claro que el hecho de que las Res Gestae Divi Augusti contradigan a otras fuentes indica que los autores posteriores no se dejaron influenciar por lo escrito por el primer emperador de Roma. También, como señalan Grenade y Herrmann, demuestra que Augusto tuvo interés en falsificar la verdad por lo que es de suponer que trató la época triunviral, más que ninguna otra, con intención de no crear polémica o con el deseo de hacer olvidar las ilegalidades de aquel periodo?.

Las informaciones aportadas por estas tres fuentes clásicas son lo único que tenemos del juramento del año 32 a. C. ya que el texto exacto no se conoce pero han llegado hasta nosotros otros juramentos de fidelidad realizados en el Occidente romano (existen otros realizados en Oriente, pero 
nuestro estudio se centra en los de la parte occidental porque fue la implicada en el juramento del 32 a. C.) que, en conjunto, nos pueden dar una idea bastante aproximada del contenido del juramento.

En primer lugar nos podemos fijar en el juramento hecho por los italianos, en el año 91 a. C., al tribuno Livio Druso, quien contó con el apoyo de toda Italia, como señala Floro, porque incluyó a los itálicos en su programa de concesión de la ciudadanía ${ }^{10}$. Muchos, en Roma, se mostraron reticentes a esta medida pero este tribuno lo hizo para encontrar un nuevo punto de apoyo sobre el cual poder afianzar su programa. En circunstancias parecidas se realizó el del año 32 a. C. ya que Octaviano lo que buscaba era afianzar su posición frente a Marco Antonio.

Según Syme, recordaría a la promesa solemne del Senado a César realizada poco tiempo antes del asesinato de éste, y al juramento prestado en Tívoli al cónsul Marco Antonio, de finales del año 44 a. C. ${ }^{11}$ En la laudatio funebris de Marco Antonio a César, siguiendo a Apiano, el lugarteniente del dictador asesinado recordó el juramento por el cual todos se comprometían a proteger a César, al cuerpo de éste y a exterminar a los que no le vengaran en caso de que alguien conspirase contra César ${ }^{12}$. También Apiano nos informa de que los soldados bajo el mando de Marco Antonio y los veteranos que habían acudido a Tívoli juraron voluntariamente que no faltarían a la amistad ni a la fidelidad hacia Marco Antonio ${ }^{13}$. Según Herrmann, este juramento de Tívoli habría sido un modelo para la acción del año 32 a. C. ya que el realizado a Marco Antonio se hizo en un ambiente de inminente guerra civil (el enfrentamiento de éste con Octaviano y el Senado) como el prestado a Octaviano aunque la diferencia entre ambos es que el del año $32 \mathrm{a}$. C. incluyó a civiles y no únicamente a militares como el de Tívoli ${ }^{14}$.

Es muy probable que la fórmula del juramento del año $32 \mathrm{a}$. C. fuera similar a la que aparece en la tabula de bronce que recoge el juramento hecho por la ciudad de Conobaria comprometiéndose, en el año 6-5 a. C., a defender a Augusto y a los miembros varones de la domus Augusta con motivo de la deductio in forum del joven $\mathrm{Gayo}^{15}$. Un juramento contemporáneo al de los conobarienses es el realizado, en los territorios de la parte oriental bajo dominio romano, por la ciudad de Samos, que se habría tomado, a iniciativa de la propia ciudad, como respuesta a la aceptación por Augusto de su XII consulado para el año 5 a. C. y la deductio in forum del joven Gayo, como en el caso del de Conobaria $^{16}$. Otro que podemos mencionar, perteneciente también a los territorios orientales, es el de Paflagonia, fechado el 6 de marzo del año 3 a. C., que fue prestado a Augusto, tras la anexión de este territorio al Imperio, por toda la provincia, incluyendo la población nativa y los ciudadanos romanos ${ }^{17}$.

Seguidamente reproducimos el juramento de los conobarienses: 
P(ublio) PETRONIO T(iti) F(ilio) TERPILIANO PROCO(n)S(ule)] / M(arco) ALFIO G(ai) F(ilio) LACHETE [QVASTORE (o LEGATO PR(o) PR(aetore)] / T(itus) QVINCTVS T(iti) F(ilius) SILO P(o D) [- - MAGISTRI ET] / SENATVS ET POPVLVS CO[NOBARIENSIVM] / IN EA VE[RBA IVRAVERVNT] / [E]X MEI ANIMI SENTENTIA VT EG[O PRO SALVTE] / HONORE VICTORIA IMP(eratoris) CAESA[RIS DIVI F(ilii)] / AVGVSTI PONTV[FIC]IS MAXVM[I ET G(ai) CAESARIS] / [A]VGVSTI F(ilii) PRINC[IP]IS IV $\langle$ V ENTVTIS C[O(n)S(ulis) DESIGN(atii)] / PONTVFICIS ET PRO L(ucii) CAESARIS AVG[usti F(ilii) et M(arci)] / AGRIPPAE AVGVSTI NEPOTIS SENTEN[NTIAM] / FACIAM ARMA CAPIAM EOSDEM [AMICOS] SOCIOSQVE QVOS EIS ESSE INTEL[LEXERO] / HABEBO EOSDEMQVE INIMICOS M[EOS ESSE] / STATVAM QVOS EORVM PARTIBVS [ANIMAD-] / VERTERO ET SI QVIS ADVERSVS [EOS ALIQVID] / FECERINT SENSERINT EOS TERR[A MARIQVE VSQVE] / AD INTERNICIONEM PERSEQVA[R - - - ]

Siendo procónsul Publio Petronio Turpiliano, hijo de Tito, cuestor (o legado propretor) Marco Alfio Laques, bijo de Gayo, los magistrados Tito Quinto Silón, bijo de Tito y P. (o D.)... y el senado y el pueblo de los conobarienses prestaron juramento con estas palabras: que yo francamente por la salud, honor y victoria del emperador César Augusto, bijo del Divino, pontifice máximo y de Gayo César, bijo de Augusto, príncipe de la juventud, cónsul designado, pontífice y de Lucio César, hijo de Augusto, y de Marcio Agripa, nieto de Augusto, tomaré la resolución de tomar las armas y tendré los mismos amigos y aliados que haya comprendido que ellos tienen y declararé que son mis enemigos los que están en la facción de éstos. Y si alguien haya hecho o pensado algo contra ellos, los perseguiré por tierra y por mar hasta su total destrucción.

La fórmula de esta tabula se repite en una placa cuadrangular de bronce realizada, en el año 37 d. C., por los aricienses al emperador Calígula ${ }^{18}$.

C(aio) VMMIDIO DVRMIO QVADRATO / LEG(ato) C(aii) CAESARIS GERMANICI IMP(eratoris) / PRO PRAET(ore) / IVSIVRANDVM ARITIENSIVM / EX MEI ANIMI SENTENTIA VT EGO IIS INIMICVS / ERO QVOS C(aio) CAESARI GERMANICO INIMICOS ESSE / COGNOVERO ET SI QVIS PERICVLVM EI SALVTIQ $(u e)$ EIVS / IN[F]ER[T] IN[TVL]ERIT[V]E ARMIS BELLO INTERNECIVO / TERRA MARIQ $(u e)$ PERSEQVI NON DESINAM QVO AD / POENAS EI PERSOLVERIT NEQ[V]E LIBEROS MEOS / EIVS SALVTE CARIORES HABEBO EOSQ(ue) QVI IN EVM HOSTILI ANIMO FVERINT MIHI HOSTES ESSE / DVCAM SI S[CIE]NS 
FA[LL]O FEFELLEROVE TVM ME / LIBEROSQ(ue) MEOS IVPPITER OPTIMVS MAXIMVS AC / DIVVS AVGVSTVS CETERIQ $(u e)$ OMNES DI IMMORTALES / EXPERTEM PATRIA INCOLVMITATE FORTVNISQVE / OMNIBVS FAXINT [A(nte) D(iem)] V (quintum) IDVS MAI(as) IN / ARITIENSE OPPIDO VETERI CN(aeo) ACERRONIO / PROCVLO C(aio) PETRONIO PONTIO NIGRINO $\mathrm{CO}(\mathrm{n}) \mathrm{S}$ (ulibus) / MAG(istris vel istratibus) / VEGETO TALTICI [...] [V]IBIO [...]ARIONI

Siendo Gayo Umidio Durmio Quadrato legado propretor del emperador Gayo César Germánico-juramento de los aricienses:

Que, en mi conciencia, seré enemigo de aquellos que puedan ser o sean de Gayo César Germánico; y si alguien lo pusiera en peligro, para procurar su bienestar, no me cansaré de perseguirlo, interviniendo con las armas, en la guerra, en tierra o en mar, para aplicar el castigo, no estimando más la vida de mis hijos que la vida de él; consideraré mis enemigos a aquellos que lo hostiguen. Si, conscientemente, falto of fuera a faltar al juramento, conociéndolo Júpiter Óptimo Máximo y el divino Augusto y todos los otros dioses inmortales me priven, a mi y a mis hijos, de la patria, de la seguridad personaly de toda la buena suerte.

En el quinto día antes de los idus de mayo (11 de mayo), en la ciudad de Aricio, siendo cónsules Gneo Acerronio Proculo y Gayo Petronio Poncio Nigrino [año 37 d. C.] y magistrados Vegeto, hijo de Taltico y Vibio, hijo de...

Estos dos juramentos de época imperial siguen la siguiente estructura: el juramento.

1. Los nombres de los magistrados romanos del año en el que se realiza

2. El que presta el juramento.

3. En qué consiste el juramento y a quien se le presta.

4. El castigo para quien incumpla el juramento (en el caso del de los aricienses).

5. La fecha (aparece en el de los aricienses).

Es probable que el texto del juramento a Octaviano estuviera estructurado de una forma similar. Así, en él aparecerían Italia y las provincias occidentales prestando a Octaviano un juramento de carácter personal ya que, siguiendo a Syme, el del año 32 a. C. no haría referencia ni al Senado ni al Estado romano ni al pueblo, puesto que todos estos territorios quedarían vinculados a un jefe político, Octaviano, en caso de una desavenencia privada contra sus enemigos personales pero no contra los hostes, los enemigos del 
Estado, no pudiendo cambiar nunca ni expirar ${ }^{19}$. También Octaviano, mediante el juramento, fue designado cónsul para el año siguiente y, según Millán Méndez, lo autorizaba a realizar una leva ilimitada ${ }^{20}$. El castigo para quien incumpliera el juramento sería parecido al que aparece en el juramento de los aricienses (aunque sin hacer referencia al divino Augusto). Cabe la posibilidad de que se estableciera la pena de ejecutar a aquellos que no vengaran a Octaviano en caso de que alguien conspirara contra éste, igual que en el juramento a César, según nos ha transmitido Apiano ${ }^{21}$. En cuanto a la fecha, es difícil establecer el momento exacto en el que se produjo este juramento puesto que algunos autores, como Grenade, abogan que habría seguido a la declaración de guerra, de julio del año 32 a. C., a Marco Antonio pero otros, por el contrario, son partidarios, como Herrmann, de situarlo poco antes de esa declaración de guerra ${ }^{22}$.

Por otra parte, a raíz de este juramento a Octaviano, los historiadores se han planteado cuáles eran los poderes de Octaviano en ese año 32 a. C., es decir, si todavía ejercía como triunviro o habría cesado como tal. Esta polémica se debe a que no está claro si la segunda renovación por cinco años del Segundo Triunvirato se hizo en el año 37 a. C. o en el año 36 a. C. Dependiendo de la fecha de renovación, esta nueva ampliación del poder triunviral finalizaría en el año 33 a. C. o en el año 32 a. C. Respecto a este debate, Southern sostiene que es posible que Octaviano dejase de usar el título de triunviro antes de que el acuerdo llegase a su fin, mientras que Marco Antonio lo usó mucho más tiempo ${ }^{23}$. Por el contrario, Grenade afirma que Octaviano habría guardado sin interrupción, incluso después del año 32 a. C., el poder triunviral hasta que él mismo le dio al Estado una nueva organización ${ }^{24}$. Lo cierto es que, como señala Millán Méndez, la jura de los senadores (quienes le acompañaron en número de 300, según las Res Gestae Divi Augusti) implicaba una concesión de plenos poderes y le daba una nueva forma de imperium que era superior al triunviral ${ }^{25}$.

Otro aspecto que debemos destacar es el círculo de personas al que hacía referencia este juramento. En Italia, según Wells, resulta totalmente lógico pensar que ésta estuviera de parte de Octaviano pues veían su creciente autoridad que serviría para garantizar la estabilidad que tanto deseaba la península italiana ${ }^{26}$. Aquí, como apunta Herrmann, el juramento abarcaría a la población adulta masculina ${ }^{27}$. Además, Octaviano tomó prestada la fórmula ciceroniana de la concordia ordinum por lo que el juramento abarcaba a todos los órdenes de la sociedad. Por su parte, Piganiol sostiene que "para resistir al asalto de Oriente, Octaviano debió hacer una alianza con las clases sociales sobre las que reposaba la civilización occidental, los senadores romanos y la burguesía municipal italiana. De esta alianza entre un jefe del ejército y el Senado nació el régimen imperial" 28 . A esta afirmación podemos añadir lo que opina Johnson quien señala que la clase media italiana apoyaría a Octaviano 
porque éste hizo aparecer a Marco Antonio como alguien alejado de los cánones tradicionales romanos e itálicos de moralidad y propiedad, de las que él mismo aparecía como defensor. Otros apoyarían a Octaviano porque odiarían a Oriente y otros, simplemente, le prestarían su ayuda porque sólo el triunfo de Octaviano favorecería sus intereses comerciales o egoístas ${ }^{29}$.

En cuanto a las provincias, la idea de crear un lazo personal entre los ciudadanos y su jefe, de formar una coniuratio no resultaba ser, en absoluto, nada extraño puesto que, antes de estar bajo dominio romano, establecían vínculos entre los diversos grupos tribales y como ejemplo podemos citar el caso de las teseras de hospitalidad en Hispania. Además, muchos magnates locales, colonos o negociantes eran partidarios de la causa cesariana y es que en los territorios que comprendían la Galia Cisalpina existía un sentimiento de reconocimiento personal a César prolongado en Octaviano. A esto hay que añadir que muchos hombres de la Galia Transalpina y de Hispania, que habían sido admitidos en el Senado por César, se mantuvieran fieles al heredero de éste.

Por último, debemos señalar que el juramento del año 32 a. C. se puede interpretar como una expresión de la relación entre patrono y cliente basada en la fides. La fides era una obligación tanto del patrono como del cliente y violarla era considerado casi como un crimen religioso. Sobre ella se habrían organizado todas las relaciones políticas, sobre todo, como apunta Millán Méndez, en momentos de máxima tensión política como cuando todas las poblaciones de Italia le prestaron juramento a Livio Druso ${ }^{30}$. Además, la fides era una forma de convivencia que no estaba regida por el derecho público y de esto se sirvió Octaviano para que le prestasen su apoyo Italia y las provincias del Occidente romano ${ }^{31}$.

En definitiva, el juramento prestado a Octaviano en el año 32 a. C. tiene características especiales derivadas de las condiciones históricas del momento, de la posición y situación a quien se prestaba y de la condición de quienes lo prestaban. Lo que distingue a este juramento de todos los mencionados es la extensión del mismo, tanto territorial como personal. Esta coniuratio italiae fue un juramento de carácter político para lograr la movilización de Italia y del Occidente romano de cara a la inminente guerra contra Marco Antonio. Además, fue el que inició la práctica de jurar fidelidad al emperador.

NOTAS

${ }^{1}$ Paul Zanker, Augusto y el poder de las imágenes. Madrid, Alianza Editorial, 2005, pág. 97. 
${ }^{2}$ Cfr. Jean Michel Roddaz, Marcus Agrippa. Roma, École Française de Rome, 1984, pág. 139.

${ }^{3}$ Cfr. Pat Southern, Mark. Antony. Gloucestershire, Tempus, 1998, pág. 133.

${ }^{4}$ Ronald Syme, La revolución romana. Madrid, Taurus, 1989, pág. 353.

${ }^{5}$ Cfr. Ronald Syme, op. cit., pág. 353.

${ }^{6}$ Ronald Syme, op. cit., pág. 360.

${ }^{7}$ Ver Juan Francisco Rodríguez Neila, Confidentes de César. Los Balbos de Cádiæ. Madrid, Sílex, 1992, págs. 253-261.

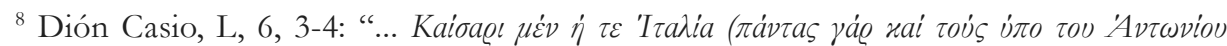

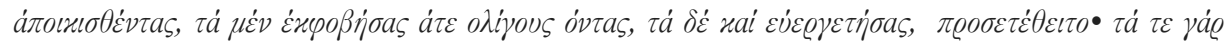

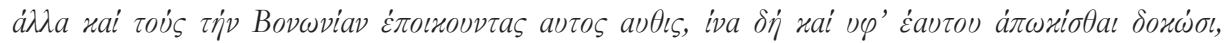

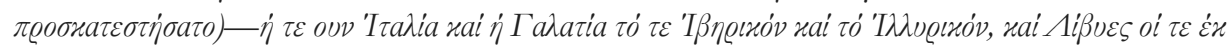

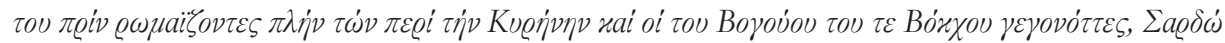

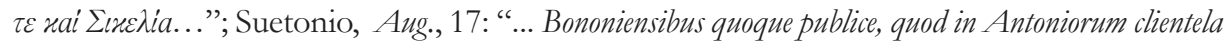
antiquitus erant, gratiam fecit coniurandi cum tota Italia pro partibus suis..."; Res Gestae Divi Augusti, 25: "... Iuranit in mea nerba tota Italia sponte sua et me belli quo nici ad Actium ducem depoposcit. Iura uerunt in eadem uerba proninciae Galliae Hispaniae Africa Sicilia Sardinia. Qui sub signis meis tum militauerint fuerunt senatores plures quarm DCC...".

${ }^{9}$ Cfr. Peter Herrmann, Der Römische Kaisereid: Untersuchungen zu seiner Herkunft und Entwicklung. Göttingen, Vandenhoeck \& Ruprecht, 1968, pág. 80; Pierre Grenade, Essai sur les origines du Principat: investiture et renouvellement des pouvoirs imperiaux. París, Édition de Boccard, 1961, pág. 3.

${ }^{10}$ Floro, II, 5.

${ }^{11}$ Cfr. Ronald Syme, op. cit., pág. 364.

${ }^{12}$ Apiano, B. Civ., II, 145.

${ }^{13}$ Apiano, B. Civ., III, 46.

${ }^{14}$ Cfr. Peter Herrmann, op. cit., pág. 84.

${ }^{15}$ Ver Julián González Fernández, Corpus de inscripciones latinas de Andalucía. Vol. II, Sevilla. T. III, La Campiña. Sevilla, Consejería de Cultura y Medio Ambiente de la Junta de Andalucía, Dirección General de Bienes Culturales, 1996, págs. 345-349; Julián González Fernández, Bronces jurídicos romanos de Andalucía. Sevilla, Junta de Andalucía, Consejería de Cultura, 1990, págs. $175-178$.

${ }^{16}$ Cfr. Julián González Fernández, "El origen del culto imperial en la Betica según la documentación epigráfica” en Trinidad Nogales Basarrate y Julián González Fernández (eds.), Culto imperial: politica y poder: actas del Congreso Internacional Culto Imperial: politica y poder. Roma, L’Erma di Bretschneider, 2007, págs. 175-188, pág. 186.

${ }^{17}$ Para ver las teorías expuestas sobre la génesis de este documento Julián González Fernández, art. cit., pág. 186. 
${ }^{18}$ Ver D’Encarnação, José, Inscrições romanas do Conventus Pacensis. Subsídios para o estudo da Romanização. Vol. I y II. Coimbra, Instituto da Arquelogia da Facultadade de Letras, 1984, págs. 703-706, 752-753; María Amélia Horta Pereira, Monumentos históricos do Concelho de Mação. Mação, Câmara Municipal de Mação, 1970, págs. 314-315; Álvaro d’Ors, Epigrafía jurídica de la España romana. Madrid, Ministerio de Justicia y Consejo Superior de Investigaciones Científicas, 1953, págs. 21-24.

${ }^{19}$ Cfr. Ronald Syme, op. cit., págs. 364-365.

${ }^{20}$ Cfr. A. Millán Méndez, "Sacramentum militiae. Características del juramento prestado a Octavio el año 32 a. C.”. Hispania Antiqua. Revista de Historia Antigua, vol. VI, (Valladolid, 1976), págs. 27-42, pág. 34.

${ }^{21}$ Apiano, B. Civ., II, 145.

${ }^{22}$ Cfr. Pierre Grenade, op. cit., pág. 20; Peter Herrmann, op. cit., pág. 80.

${ }^{23}$ Cfr. Pat Southern, op. cit., pág. 130.

${ }^{24}$ Cfr. Pierre Grenade, op. cit., pág. 29.

${ }^{25}$ Cfr. A. Millán Méndez, art. cit., pág. 33.

${ }^{26}$ Cfr. Colin Wells, El Imperio Romano. Madrid, Taurus, 1986, pág. 26.

${ }^{27}$ Cfr. Peter Herrmann, op. cit., pág. 80.

${ }^{28}$ André Piganiol, La conquête romaine. París, Presses Universitaires de France, 1974, pág. 566.

${ }^{29}$ Cfr. John Robert Johnson, Augustan Propaganda: the Battle of Actium, Mark. Antony's will, the Fasti Capitolini Consulares and Early Imperial Historiography. Ann Arbor, University Microfilms Internacional, 1980, pág. 13.

${ }^{30}$ Cfr. A. Millán Méndez, art. cit., pág. 35.

${ }^{31}$ Cfr. A. Millán Méndez, ibidem, pág. 35. 